\title{
Estimating wheat crop production by using different small area techniques
}

D.G. NAJEER AHMAD AND VINAYAK N. JALIKATTI

Received : 12.03.2014; Revised : 24.07.2014; Accepted : 11.08.2014

\begin{abstract}
Small area estimates often is necessary since today in the context of regional planning, the distribution of the central funds may be made on a local or regional basis and may depend on variables such as the principal occupation of household, number of members of the family unemployed and economic status of the families. The small area estimates at micro-level (small area) are now in great demand by Village Panchayat as well as private sectors in order to prepare policy formulation for research and development process specific to small areas on the basis of economic status of the households. The study revealed that the estimates of wheat yield of Bagalkot district varied from 2245 to $2285 \mathrm{~kg}$ per hectare while, wheat yield of Dharwad district varied from 1645 to $1675 \mathrm{~kg}$ per hectare. The average yield of wheat in Bagalkot district was more (23.86 quintals per hectare) than that of Dharwad (16.21 quintals per hectare).
\end{abstract}

KEY WORDS : Wheat crop, Production, Small area techniques

How to cite this paper: Ahmed, D.G. Najeer and Jalikatti, Vinayak N. (2014). Estimating wheat crop production by using different small area techniques. Internat. J. Com. \& Bus. Manage, 7(2): 251-255. 